\title{
THE INTRINSIC FLUORESCENCE OF TETRAHYMENA AS A FUNCTION OF TEMPERATURE
}

\author{
by \\ ROBIN J. HILL') and ERIK ZEUTHEN*
}
The Biological Institute of the Carlsberg Foundation, Tagensvej 16, DK-2200 Copenhagen N

1) Present address: Department of Experimental Immunology, University of Copenhagen

Keywords: Intrinsic fluorescence, cell synchrony, Tetrahymena membranes

Washed suspensions of Tetrahymena pyriformis GL have an intrinsic fluorescence with an excitation maximum at $291 \mathrm{~nm}$ and an emission peaking at $358 \mathrm{~nm}$. These wavelengths are characteristic for protein fluorescence. When suitable optical filters are used to eliminate scattered light, a sharp increase in the fluorescence is seen on heating the suspensions. The increase in fluorescence starts at $32{ }^{\circ} \mathrm{C}$ and peaks at $36^{\circ} \mathrm{C}$, with a mid-point at $34^{\circ} \mathrm{C}$. The fluorescence-temperature profile does not change during the cell cycle.

On starving the cells in inorganic medium, the fluorescence decreases markedly within a few hours, but reappears when the cells are transferred to a nutrient medium. Slight shifts in the temperature at which maximal fluorescence is seen were noted as cultures grew denser, and large shifts were observed when the culture temperature was altered. These shifts suggest that the conformation of the proteins responsible for the fluorescence emission is in some way determined by the state of the cell membrane. The local anæsthetic dibucaine was able to titrate out the fluorescence, although cytochalasin B and colchicine had no effect, again suggesting that the fluorescence is controlled by the membrane state.

Reversal experiments demonstrated that although the fluorescence was not affected by heating up to $32{ }^{\circ} \mathrm{C}$, it was greatly diminished when the cells were heated above $35^{\circ} \mathrm{C}$. Damaging the cells by other means, e.g. by brief sonication at low power or by shaking the cell suspensions, also resulted in a decrease in the fluorescence.

Two other species of Tetrahymena, $\mathrm{T}$. vorax $\mathrm{V}_{2} \mathrm{~S}$ and $\mathrm{T}$. thermophila $(\mathrm{Mpr}-\mathrm{V})$ showed similar increases in fluorescence at temperatures a few degrees above their growth temperature. In the latter case, the mid-point of the fluorescence-temperature profile corresponds to the synchrony temperature, as is also the case with $\mathrm{T}$. pyriformis GL.

\footnotetext{
* Deceased on January 10th, 1980.
}

Abbreviation: $\mathrm{IM}=$ inorganic medium. 


\section{INTRODUCTION}

The experiments described in this paper were initiated in the hope that further light could be cast on the effect of heat shocks on cultures of Tetrahymena. ZEUTHEN (29) introduced the method of inducing synchrony in a population of Tetrahymena pyriformis GL by administration of a series of half hour heat shocks spaced at intervals corresponding to a generation time. This method of inducing synchrony has since been applied with partial success to other species of Tetrahymena, such as T. thermophila (28) and with more success, to a yeast (15).

It has been well documented that the heat shock results in morphogenetic changes in the developing oral apparatus of Tetrahymena (14), suggesting that one of the effects of heat might be on the outer membrane system, or on the cytoskeletal elements, including those associated with the mouth apparatus. In line with this interpretation are the findings of ERwIN and coworkers $(9,19)$, who demonstrated numerous distortions of the cell surface topography as a result of culturing $\mathrm{T}$. pyriformis strain $\mathrm{WH} 14$ at sublethal temperatures. As these morphological changes could be reversed by supplementing the growth medium with polyunsaturated fatty acids, ERwIN and his colleagues suggested that the lesions were due to defective fatty acid biosynthesis at the higher growth temperature. Whether such heat-induced changes associated with the membrane systems are in any way connected with the delay in division, so essential for successful synchrony, is still an open question.

In addition to the morphological changes described above, there is considerable evidence indicating that disturbances to the protein metabolism occur during heat shock $(2,4,5)$, and in particular the ribosomes' capacity to synthesize protein is affected (3). Levy et al. (18) observed that protein synthesis in T. pyriformis strain $\mathrm{E}$ was greatly inhibited at elevated temperatures (from $33.5^{\circ} \mathrm{C}$ to $34^{\circ} \mathrm{C}$ ). Parallel ultrastructural studies revealed multiple lesions of all types of cell organelles, including loss of tubules from mitochondria and complete disappearance of the rough endoplasmic reticulum.

Both ERwiN's and Levy's studies show that various membrane structures become distorted after extended periods at sublethal temperatures.
Within the normal growth-temperature range one of the immediate responses of Tetrahymena to an increase in ambient temperature is to activate a compensatory system which ensures that the membrane fluidity returns to the normal level. This is achieved by the deactivation of a fatty acid desaturase $(21,27)$, the interesting point here being that it appears that the activity of this membrane-bound enzyme is in itself regulated by the fluidity of the membrane. This is yet another illustration of the fact that the conformation and hence the activity of an integral membrane protein can be markedly affected by the fluidity of the lipid components of the membrane (12).

In the experiments reported here, it is shown that the intrinsic fluorescence, which is an indicator of a proteins' conformation (7), increases dramatically when washed suspensions of Tetrahymena are heated above the growth temperature. This increase in fluorescence is probably not due to denaturation of the protein (i.e. an irreversible conformational change), since the temperature at which the fluorescence increases varies according to the growth temperature. It seems more likely that there is a causal relationship such that a change in membane lipid fluidity, as would be caused by elevated temperatures, leads to a conformational change of certain proteins, which in turn is reflected by changes in the intensity of the fluorescence emission.

\section{MATERIALS AND METHODS}

\subsection{Chemicals}

All chemicals were of analytical grade quality. Dibucaine- $\mathrm{HCl}$ was a generous gift from CibaGeigy, Copenhagen.

\subsection{Cultures}

$15 \mathrm{ml}$ cultures of $\mathrm{T}$. pyriformis $\mathrm{GL}$ in $2 \%$ proteose peptone with $0.1 \%$ liver extract (Difco) and $0.04 \mu \mathrm{mol} \mathrm{FeCl}_{3}$ were grown to a density of about $10^{5}$ cells $\cdot \mathrm{ml}^{-1}$ in $150 \mathrm{ml}$ Erlenmeyer flasks shaken slowly at $28^{\circ} \mathrm{C}$. Unless otherwise stated, cultures of other strains of Tetrahymena were grown at their optimal growth temperature without shaking and washed as described below. A methylpurine resistant strain of $\mathrm{T}$. thermo- 


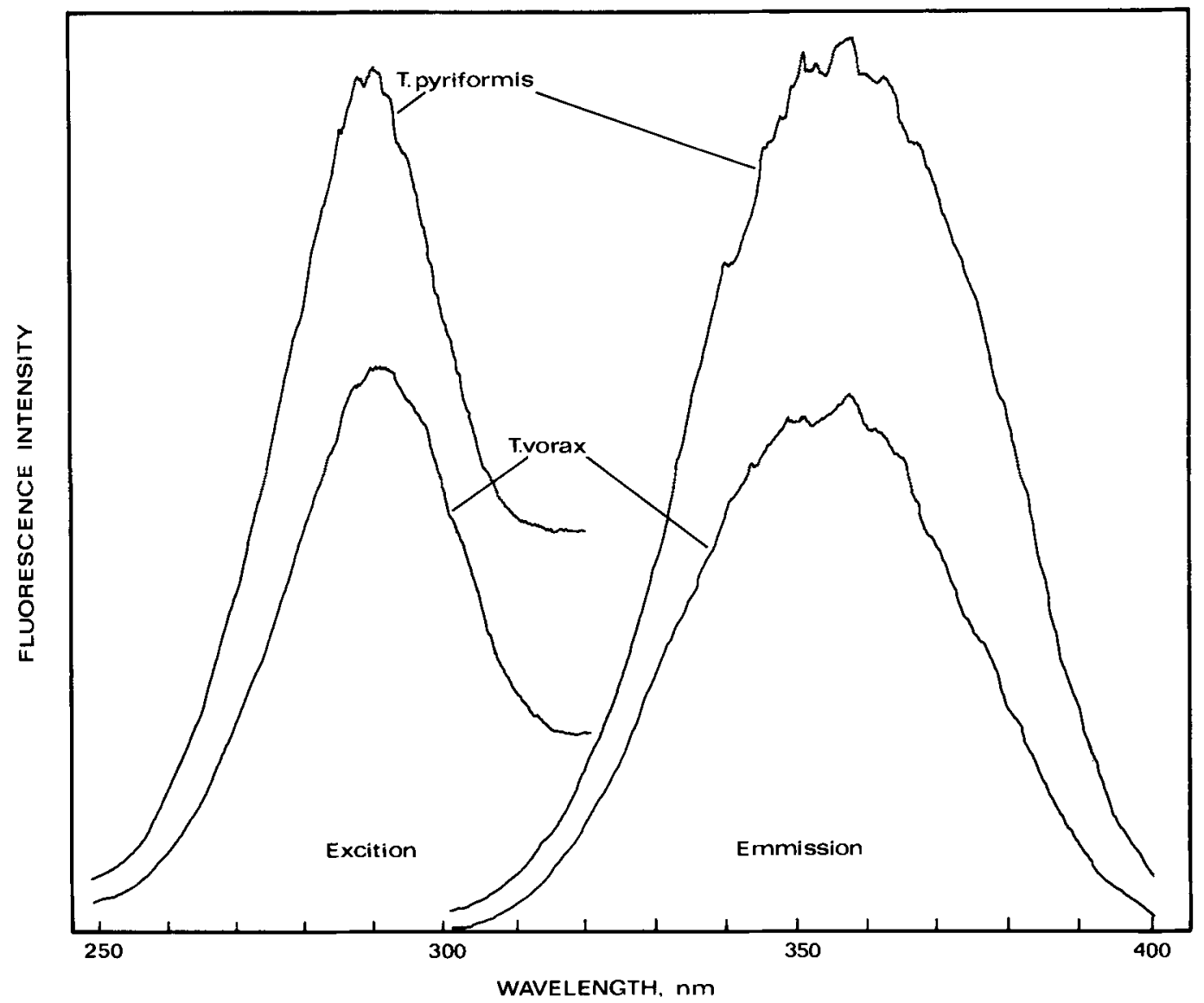

Figure 1. Excitation and emission spectra of washed suspensions of T. pyriformis GL (upper curves) and T. vorax $\mathrm{V}_{2} \mathrm{~S}$ (lower curves).

Cells cultured at $28{ }^{\circ} \mathrm{C}$ in gently rotated Erlenmeyer flasks were washed with $28^{\circ} \mathrm{C}$ inorganic medium. The washed suspensions were placed in a $10 \mathrm{~mm}$ fluorescence cuvette thermostated at $22.1^{\circ} \mathrm{C}$ and scanned within 10 minutes at $40 \mathrm{~nm} \cdot \mathrm{min}^{-1}$ using a time constant of $2 \mathrm{sec}$. The half band width $(\lambda / 2)$ of both monochromators was $9 \mathrm{~nm}$. The T. pyriformis suspension had a density of $3 \times 10^{4} \mathrm{cells} \cdot \mathrm{ml}^{-1}$, and the T. vorax a density of $1.4 \times 10^{4}$ cells $\cdot \mathrm{ml}^{-1}$. The same spectra were obtained when scanning at $28^{\circ} \mathrm{C}$.

phila (Mpr-V) was grown at $28^{\circ} \mathrm{C}$ in $2 \%$ proteose peptone with $0.1 \%$ yeast extract and $0.04 \mu \mathrm{mol} \mathrm{FeCl}_{3}$, and washed in $\mathrm{pH} \mathrm{7.2,10}$ mmol Tris buffer at the same temperature. $\mathrm{Mpr}-\mathrm{V}$ was made available by courtesy of Dr. PETER BRUNS.

\subsection{Fluorescence measurements}

For the measurement of the intrinsic fluorescence of the cultures, samples were centrifuged at $800 \times \mathrm{g}$ for $3 \mathrm{~min}$, and the loose cell pellet washed twice in an inorganic medium containing glucose (IM) at $28^{\circ} \mathrm{C}$. (IM is made up as follows: $\mathrm{KH}_{2} \mathrm{PO}_{4} 0.15 \mathrm{~g}, \mathrm{~K}_{2} \mathrm{HPO}_{4} 0.68 \mathrm{~g}$, $\mathrm{MgSO}_{4} .7 \mathrm{H}_{2} \mathrm{O} 0.25 \mathrm{~g}, \mathrm{NaCl} 1.75 \mathrm{~g}$, and glucose $7.21 \mathrm{~g}$ for 1 litre solution). The washed pellet was resuspended in the warm IM to a final concentration of about $5 \times 10^{4} \mathrm{cells} \cdot \mathrm{ml}^{-1}$, and after removing an aliquot for cell counting, $2 \mathrm{ml}$ were transferred to a $10 \mathrm{~mm}$ quartz fluorescence cuvette placed in the thermostated compartment of a modified Aminco Bowman spectrophotofluorimeter. The excitation and emission spectra of two species of Tetrahymena are shown in Figure 1. The excitation maxima for the two 
species are at about $291 \mathrm{~nm}$ while the emission is strongest at about $358 \mathrm{~nm}$. Fluorescence spectra such as those shown are characteristic for proteins containing tryptophan residues; if these residues are located internally, the emission is usually around $320 \mathrm{~nm}$, while if the tryptophans are partially exposed to the aqueous environ-

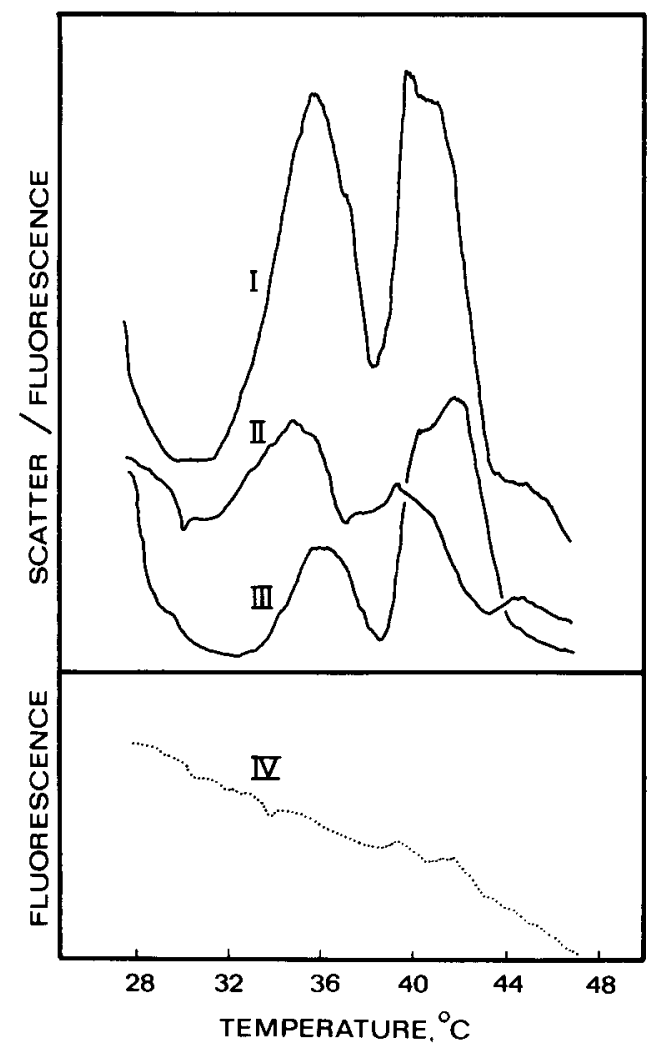

Figure 2. Curves I and II: Variation of fluorescence of $T$. pyriformis GL with temperature. Cells in the logarithmic phase of growth were washed in inorganic medium at $28^{\circ} \mathrm{C}$, and after 7 min their fluorescence emission at $340 \mathrm{~nm}$ was measured as a function of temperature. Excitation was at $285 \mathrm{~nm}$ : $\lambda / 2=9 \mathrm{~nm}$; time constant $29 \mathrm{sec}$; light path $1 \mathrm{~mm}$; rate of change of temperature $0.6^{\circ} \mathrm{C} \cdot \mathrm{min}^{-1}$. I: $4.3 \times 10^{4}$ cells $\cdot \mathrm{ml}^{-1} ; \mathrm{II}: 2.9 \times 10^{4} \mathrm{cells} \cdot \mathrm{ml}^{-1}$.

Curve III: Variation of scattered light of a suspension of $\mathrm{T}$. pyriformis GL, $4.3 \times 10^{4} \mathrm{cells} \cdot \mathrm{ml}^{-1}$, as a function of temperature. Conditions as above, except that both monochromators were set at 285 nm.

Curve IV: Variation of fluorescence with temperature of a 1:100 dilution of growth medium (proteose peptone/yeast extract/iron) in inorganic medium. Experimental conditions as for curves I and II. ment, the emission is red-shifted to about 350 nm (7).

The temperature of the cell suspensions was measured continuously by means of a Mettler TM1 thermistor placed in one corner of the cuvette, out of the light path. The fluorescence was plotted as a function of temperature on a Texas X-Y recorder. The heating and cooling rates were usually $0.6^{\circ} \mathrm{C} \cdot \mathrm{min}^{-1}$, although heating rates of up to $1.3^{\circ} \mathrm{C} \cdot \mathrm{min}^{-1}$ were occasionally employed without this having any effect on the observed results.

When the fluorescence of the washed cells was followed with temperature, marked changes were seen at temperatures a few degrees above the optimal growth temperature $\left(28^{\circ} \mathrm{C}\right)$. Initially it proved impossible to obtain reproducible results, even though a variety of media of varying ionic strength and composition were used for the washing. After washing in IM two peaks were always seen, of varying relative peak height, as illustrated in Figure 2. The $285 \mathrm{~nm}$ scatter measured over the same temperature range (curve III) gave a profile very similar to that of the fluorescence (curves I and II), suggesting that there might be a considerable scatter contribution to the fluorescence signal. By comparison, the fluorescence-temperature profile of the growth medium, shown in curve IV is featureless.

The variability in the results, as illustrated by curves I and II, was to a large extent eliminated by introducing an optical filter, Zeiss UGl, in front of the fluorescence emission monochromator. This filter removed the second peak entirely, so that thereafter only a single peak, starting at $32^{\circ} \mathrm{C}$ and peaking at $36^{\circ} \mathrm{C}$ was seen in $\mathrm{T}$. pyriformis GL suspensions. In order to establish why the second peak appears, visual observations were made on a washed suspension of cells. The thermostated compartment was removed from the fluorimeter, and mounted with the thermistor in one corner, in front of a travelling microscope. As the temperature was increased (at $0.6^{\circ} \mathrm{C} \cdot \mathrm{min}^{-1}$ ), the following changes were observed in a cell suspension which had been cultured at $28^{\circ} \mathrm{C}$ : The motility of the cells started to increase at $32^{\circ} \mathrm{C}$, reaching a maximum at about $34^{\circ} \mathrm{C}$, after which it declined rapidly, to reach zero at $36.5^{\circ} \mathrm{C}$. At this temperature the cells started to die, as shown by 

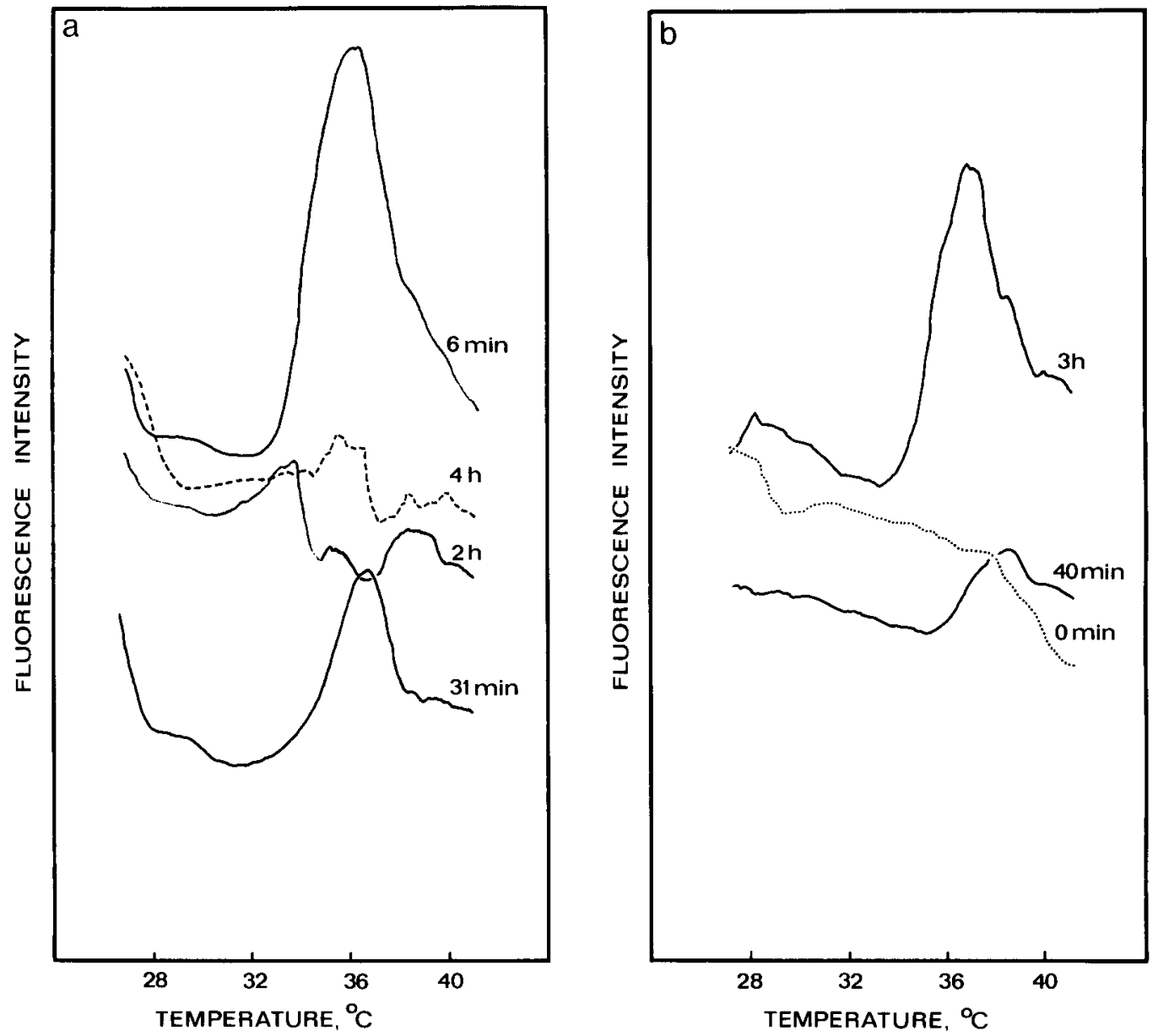

Figure 3. a: Changes in the fluorescence-temperature profiles of a washed suspension of $T$. pyriformis GL upon starvation in inorganic medium. Cells were washed in inorganic medium at $28^{\circ} \mathrm{C}$, and kept in thin layers of medium at $28^{\circ} \mathrm{C}$ for various lengths of time before measuring their fluorescence. The washed cell concentration was $11.6 \times 10^{4}$ cells $\cdot \mathrm{ml}^{-1}$. The times of starvation were as indicated. The fluorescence was measured in a 10 mm cuvette at $285 / 345 \mathrm{~nm},(\lambda / 2=9 \mathrm{~nm})$, using a time constant of $15 \mathrm{sec}$, and a Zeiss UGl filter in front of the emission monochromator to eliminate scattered light.

b: Recovery of fluorescence following transfer of cells, starved in inorganic medium overnight at $28{ }^{\circ} \mathrm{C}$, to growth medium at the same temperature. The 0 min curve shows the fluorescence-temperature profile after 16 hours in inorganic medium. The other curves show the same cells (density $5 \times 10^{4}$ cells $\cdot \mathrm{ml}^{-1}$ ) $40 \mathrm{~min}$ and 3 hours after transfer to nutrient medium. Experimental conditions as for Figure 3a.

their rounding up (swelling), and at $37^{\circ}-38^{\circ} \mathrm{C}$ blebs appeared. At $38^{\circ} \mathrm{C}$ aggregation started, and increased rapidly so that by $40^{\circ} \mathrm{C}$ aggregates consisting of several hundred cells could be seen. It thus seems reasonable to attribute the second "fluorescence « peak to scattered light reflected from the large aggregates which started to form following cell death. As a consequence, any changes in fluorescence intensity observed above $36^{\circ} \mathrm{C}$ should be interpreted with caution.
On the basis of the results illustrated in Figures 1 and 2, all subsequent experiments were carried out using an excitation wavelength of $285 \mathrm{~nm}(\lambda / 2=9 \mathrm{~nm})$, while the fluorescence emission was measured at $345 \mathrm{~nm}(\lambda / 2=9$ $\mathrm{nm}$ ), after passage through a Zeiss UGl filter to eliminate scatter. Furthermore, for reasons to be explained in the Results section, the wash time was kept to between 6 and 7 minutes. 


\section{RESULTS}

\subsection{Effect of washing time and nutritional state}

A great deal of variability in the form of the fluorescence versus temperature curve was seen despite the elimination by use of the Zeiss UGl filter of the scatter contribution to the fluorescence signal. This variability proved to be a function of the length of time between the transfer to IM and the commencement of the fluorescence measurements. Figure $3 \mathrm{a}$ shows how the fluorescence of the same cell suspension changes after washing over to IM; it can be seen that the fluorescence peak decreases drastically with time, so that within 2 hours the fluorescence-temperature curve becomes essentially featureless.

Seeing that the fluorescence peak was eliminated by transferring the cells to inorganic medium, it was to be expected that the fluorescence would reappear on transferring back to a nutrient growth medium. The same batch of cells which were used in the experiments shown in Figure 3a were starved overnight in IM, and then transferred to proteose peptone. Within 40 min, much of the fluorescence had returned, and by 3 hours the fluorescence-temperature profile was similar to that seen in normally growing cells (Figure $3 \mathrm{~b}$ ). Over the period of measurement, the re-fed cells did not divide, so the increase of the fluorescence signal must be due to changes occurring in single cells prior to the initiation of exponential growth.

Since the fluorescence of the cells was so sensitive to the level of nutrients in the medium, great care was taken in subsequent measurements to ensure that the washing with warm IM was carried out quickly (within 5-7 minutes), and the measurement of fluorescence completed within 15-20 minutes of removal of the cells from the growth medium.

\subsection{Effect of culture temperature}

The temperature at which Tetrahymena is cultured has a marked effect on the form of the fluorescence curves. In Figure $4 a$ the fluorescence-temperature curve of a $30.6^{\circ} \mathrm{C}$ culture of T. pyriformis washed in IM at $28^{\circ} \mathrm{C}$ is seen to be significantly shifted to a higher temperature when compared to a $28^{\circ} \mathrm{C}$ culture also washed
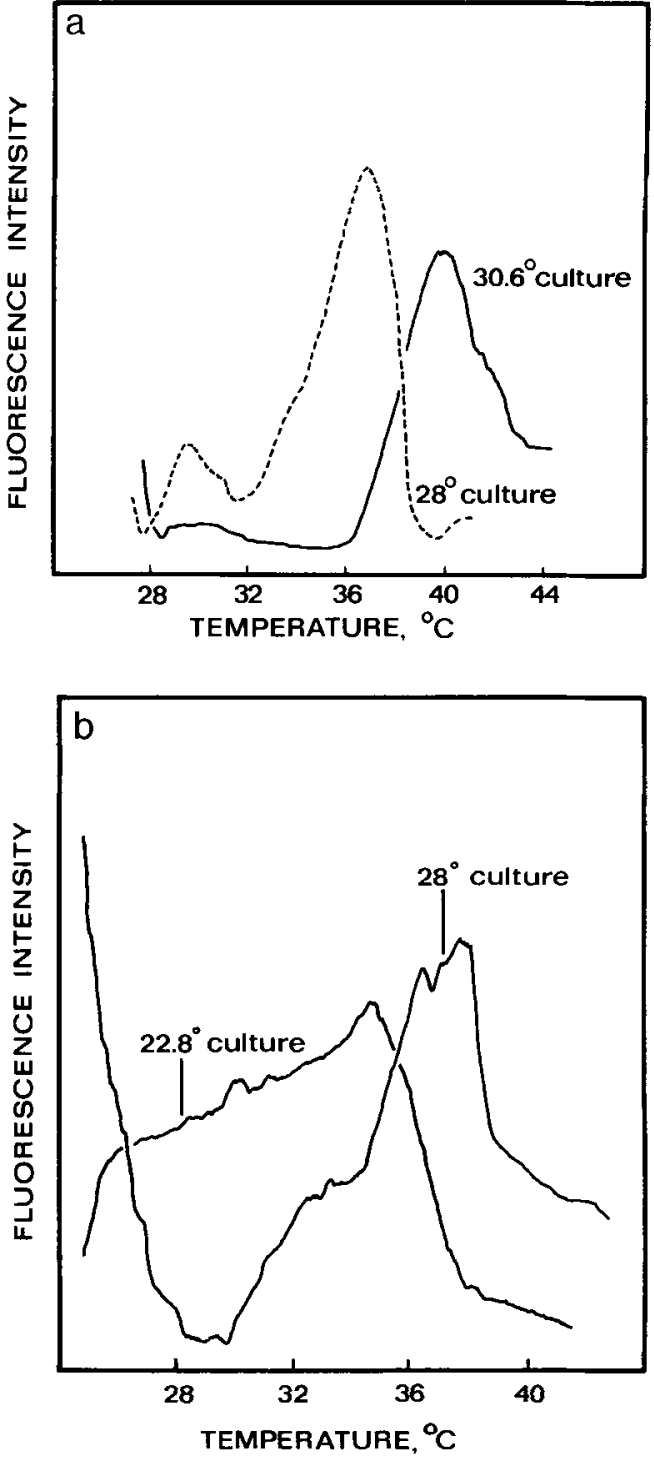

Figure 4. a: Fluorescence-temperature profiles of $\mathrm{T}$. pyriformis GL cells cultured at $28^{\circ} \mathrm{C}(\ldots)$ and $30.6^{\circ} \mathrm{C}(-)$, and subsequently washed at $28^{\circ} \mathrm{C}$. Experimental conditions as for Figure 3, but wash time $7 \mathrm{~min}$.

b: Fluorescence-temperature profiles of T. pyriformis GL cells cultured at $22.8^{\circ} \mathrm{C}$ and $28^{\circ} \mathrm{C}$ and subsequently washed at $22.8^{\circ} \mathrm{C}$. Experimental conditions as for Figure 4a.

at $28^{\circ} \mathrm{C}$. Figure $4 \mathrm{~b}$ shows the corresponding profiles of $\mathrm{T}$. pyriformis grown at $22.8^{\circ} \mathrm{C}$ and $28^{\circ} \mathrm{C}$, and subsequently washed at $22.8^{\circ} \mathrm{C}$. At the lower culture temperature, the fluorescence curve is complex, but significantly shifted to a 
lower temperature. These shifts in the curves seen following a change in the culture temperature (Figures $4 \mathrm{a}$ and $4 \mathrm{~b}$ ), may be correlated with the slow adaptive changes in the membrane composition with temperature, well known from other studies (8). It is also important to note that a $28^{\circ} \mathrm{C}$ culture when washed at $22.8^{\circ} \mathrm{C}$ (Figure 4b) gives a significantly different broad-shouldered profile when compared to the same cells cultured and washed at $28^{\circ} \mathrm{C}$ (Figure 4a). This suggests a rapid reorientation of certain proteins as a result of washing at a lower temperature. Examination of the curve for the $28^{\circ} \mathrm{C}$ culture (Figure 4a) shows that the fluorescence starts increasing at $32{ }^{\circ} \mathrm{C}$ and reaches a maximum at $36{ }^{\circ} \mathrm{C}$, with a mid-point at $34^{\circ} \mathrm{C}$ (the heat shock temperature). These initial results were stimulating since they suggested that the fluorescence signal registers a temperature-induced conformational or positional change in some protein(s) critical to the induction of heat synchrony.

\subsection{Effect of cell density and culture age}

When a culture of Tetrahymena is harvested, and a series of dilutions made from the washed cell pellet, it is seen that varying the cell density does not affect the general pattern of the fluorescence-temperature profile, the peak area being proportional to the number of cells $\cdot \mathrm{ml}^{-1}$.

Small but significant changes in the fluorescence-temperature curves are seen as the cell culture progresses from the log phase $\left(7.6 \times 10^{4}\right.$ cells $\left.\cdot \mathrm{ml}^{-1}\right)$ to the early stationary phase $\left(28.8 \times 10^{4}\right.$ cells $\left.\cdot \mathrm{ml}^{-1}\right)$ (Figure 5). As the cell density increases, the point of maximum fluorescence is seen at increasingly higher temperatures. Although the peak area increases with cell density, it is not strictly proportional to the number of cells, this being partly due to a change in the shape of the curves from a broader to a narrower form as the cell density increases. However, with cells in the early stationary phase (curve e, Figure 5), the profiles again revert to a much broader form, so that the mid-point is similar to that seen in early log phase cells.

It has been known for a long time that the content of cellular monounsaturated fatty acids decreases in dense cultures (10), which, other things being equal, would be expected to lead to an increase in the rigidity of the membranes.

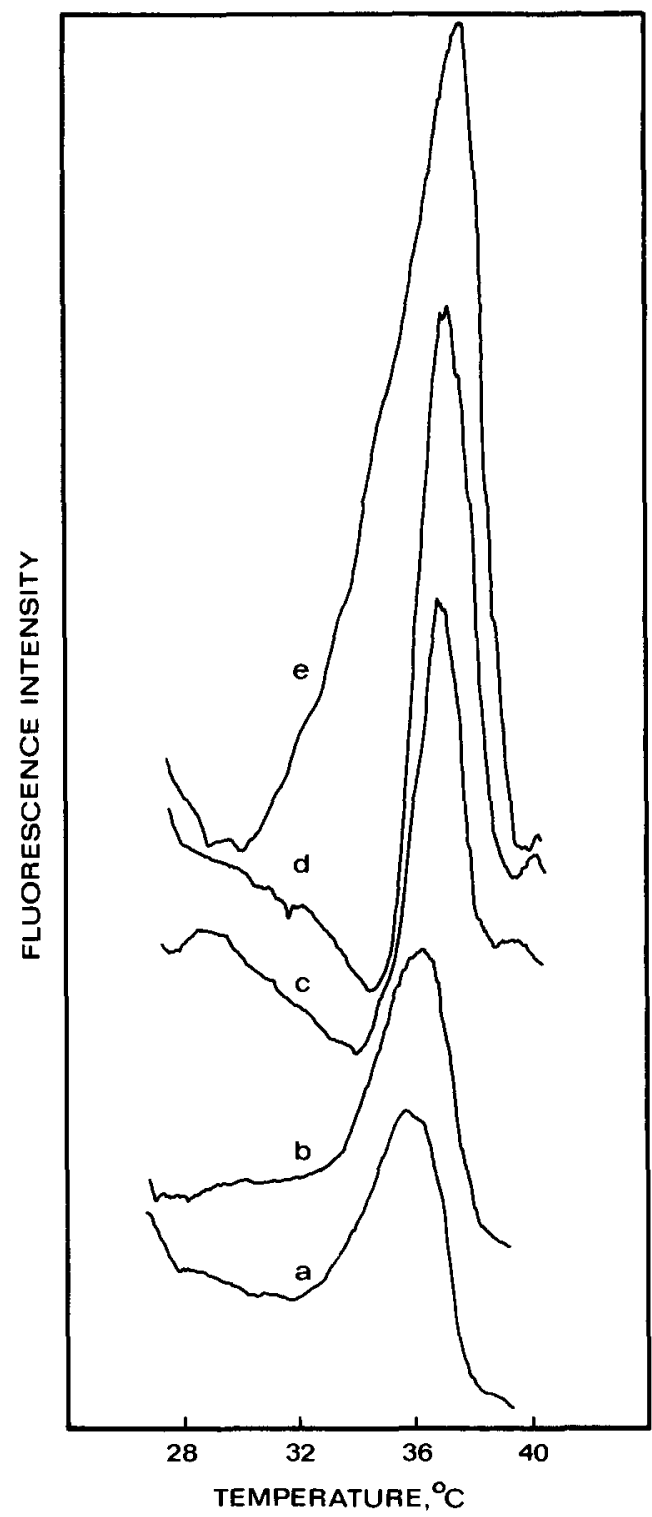

Figure 5. Effect of culture age on the fluorescencetemperature profiles of $\mathrm{T}$. pyriformis GL.

Cells, grown at $28^{\circ} \mathrm{C}$, were harvested at various cell densities, and after washing in inorganic medium at the same temperature, measured under the same experimental conditions as for Figure 4. The original culture densities, prior to washing, were as follows: a $7.6 \times 10^{4}$ cells $\cdot \mathrm{ml}^{-1}$; b. $11.2 \times 10^{4}$ cells $\cdot \mathrm{ml}^{-1}$; c. $14.8 \times 10^{4}$ cells $\cdot \mathrm{ml}^{-1} ;$ d. $20.7 \times 10^{4}$ cells $\cdot \mathrm{ml}^{-1}$ and e. $28.8 \times 10^{4}$ cells $\cdot \mathrm{ml}^{-1}$.

Thus, as will be discussed later, if the change in fluorescence with temperature indeed reflects some change in the membrane, the curves in 
Figure 5 would seem to confirm a decrease in fluidity of the membranes at high cell densities.

\subsection{Changes in the fluorescence-temperature profile during the cell cycle}

Cells were synchronised by the one heat shock per generation method (29). After the sixth shock, samples of cells in free-running synchrony were taken out and washed in inorganic

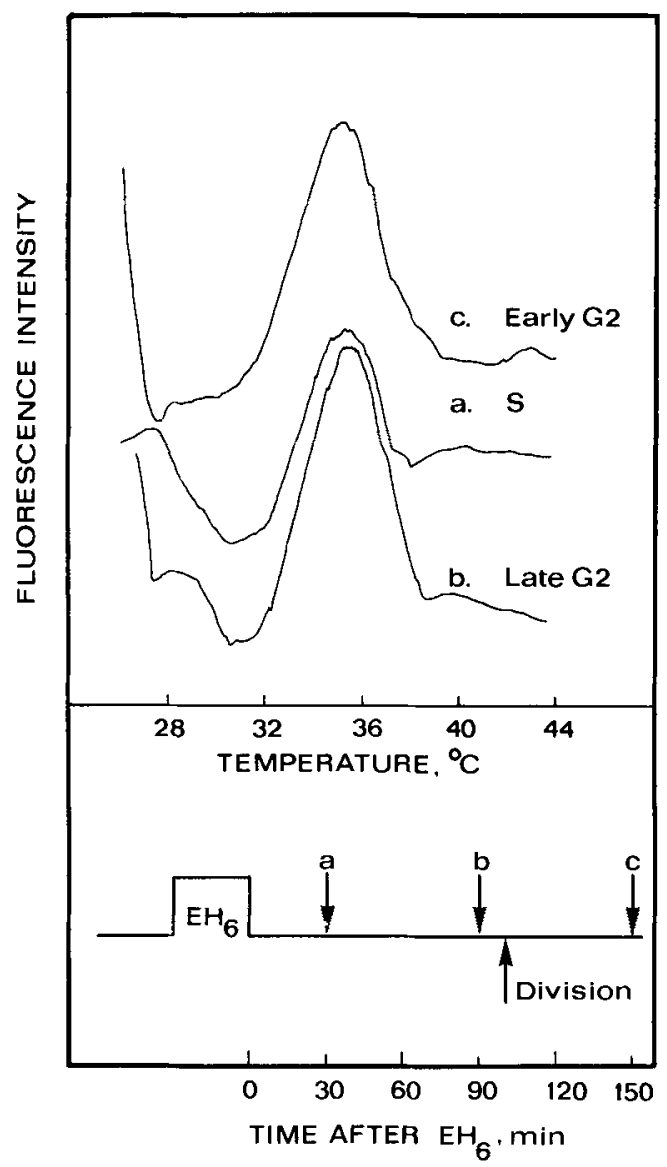

Figure 6. Fluorescence-temperature profiles of heatshock synchronized cells at various stages in the cell cycle.

A T. pyriformis GL culture was synchronized by the one heat shock per cell generation method, and after the sixth shock $\left(\mathrm{EH}_{6}\right)$, samples were withdrawn at the times indicated in the bottom half of the figure. After washing in inorganic medium at $28^{\circ} \mathrm{C}$, the fluorescence of the washed suspensions was measured under the same experimental conditions as described in the legend to Figure 4. medium as described previously. Figure 6 shows the results of the three experiments undertaken on cells from various stages in the cell cycle. No significant changes in the fluorescence-temperature profile were seen over the life cycle of the cells.

\subsection{Effect of dibucaine}

Dibucaine, a local anæsthetic which at millimolar concentrations is able to deciliate Tetrahymena, was found to have a profound effect on the fluorescence-temperature profile. At a con-

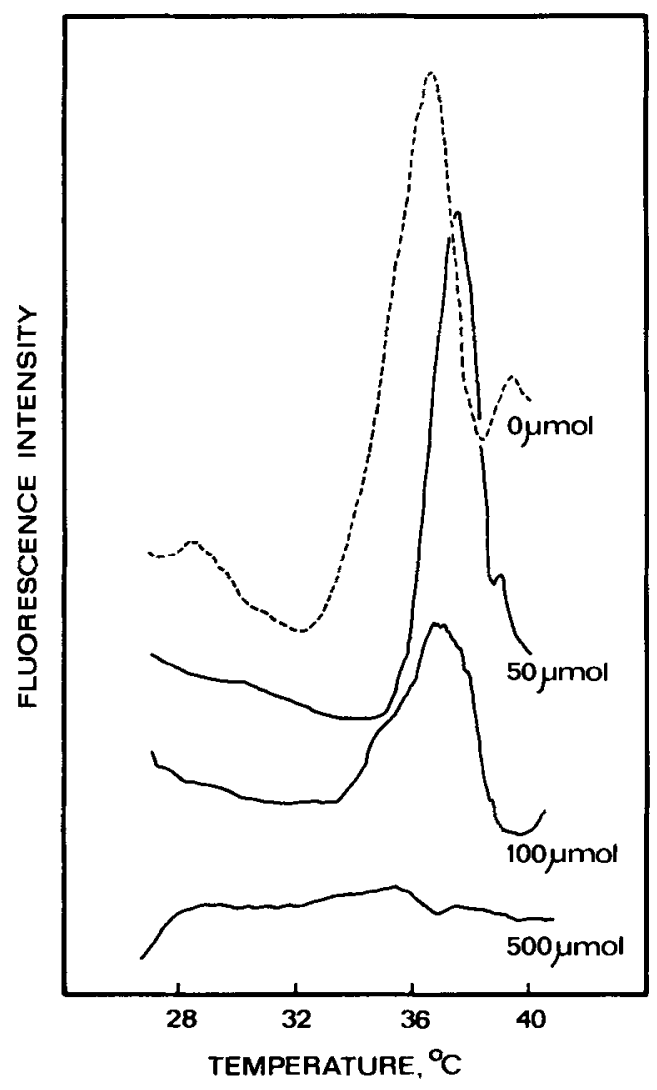

Figure 7. The effect of dibucaine on the fluorescence of suspensions of $T$. pyriformis GL.

Washed suspensions of cells were treated with an aqueous solution of dibucaine hydrochloride for 90 sec prior to recording the fluorescence under the same conditions as described in the legend to Figure 4. The final concentrations of the anæsthetic were as indicated in the figure, and the ratio (dibucaine- $\mathrm{HCl}$ (M)/ cell number) was (from top to bottom) 0 ; $6.2 \times 10^{-10} ; 14.2 \times 10^{-10}$ and $36.8 \times 10^{-10}$. 
centration ten-fold less than that required for deciliation, the intrinsic fluorescence peak is almost entirely abolished (Figure 7), whereas at intermediate concentrations, the peak is proportionally reduced. Dibucaine has been shown to have a marked effect on the fluidity of phospholipid vesicles in model systems $(16,23,26)$, although its effect on the fluidity of the plasma membrane of mammalian cells is marginal (24). However, it now appears that dibucaine also affects cytoskeletal elements (22), so the drug has at least two modes of action. Two other drugs, cytochalasin B and colchicine, which disrupt the cytoskeleton had marginal effects on the fluorescence-temperature profile (results not shown), but at such high concentrations (20-25 $\mu \mathrm{M})$ that their effect cannot be considered specific. It would thus seem most likely that dibucaine is acting on the cells by perturbing some membrane system rather than by disrupting cytoskeletal elements.

\subsection{Reversibility of the fluorescence profile}

Since the mid-point of the fluorescencetemperature profile (i.e. the point on the curve half the vertical distance between trough and peak) is $34^{\circ} \mathrm{C}$, which is also the optimal temperature for inducing synchrony by heat shocks, it was of interest to determine whether this temperature represents the point at which an irreversible change in some cellular protein(s) takes place. To do this, individual samples of washed cells, taken from a $28^{\circ} \mathrm{C}$ culture, were placed in the fluorimeter and heated up from $28^{\circ} \mathrm{C}$ to various temperatures between $30^{\circ} \mathrm{C}$ and $36^{\circ} \mathrm{C}$, and then cooled to $28^{\circ} \mathrm{C}$ again. These suspensions were then reheated to $40^{\circ} \mathrm{C}$ to see whether the usual peak appeared, or whether the initial heat treatment had changed the conformation of the protein(s). It was observed that heating to $33.8^{\circ} \mathrm{C}$ caused a marked diminution of the fluorescence peak, and a further decrease occurred in samples which had been subjected to $35.2^{\circ} \mathrm{C}$. Reversals from higher temperatures result in a complete obliteration of the fluorescence. whereas reversals from $32.8^{\circ} \mathrm{C}$ result in a fluorescence peak of normal intensity, although shifted by about $2^{\circ} \mathrm{C}$ to higher temperatures. Since the fluorescence is measured at wavelengths which are characteris- tic for proteins, it can be concluded from these reversal experiments that above the shock temperature, $34^{\circ} \mathrm{C}$, some irreversible change in the conformation of a protein occurs.

\subsection{Effect of cell damage}

During the preliminary experiments, it was noted that cells treated roughly during the washing procedure gave irreproducible fluorescence-temperature profiles. Subsequently it was shown that either rapid shaking or very mild sonication of the cells caused a diminution or complete abolition of the fluorescence peak. Only very few cells were visibly damaged by either treatment, although in both cases the motility of the cells was significantly decreased. These simple experiments showed that the integrity of the cell is an essential prerequisite for the expression of the fluorescence, and makes it extremely difficult to demonstrate experimentally that the fluorescence stems from a particular organelle.

\subsection{Fluorescence-temperature profiles of $T$. vorax and T. thermophila}

Similar experiments to those described above were carried out on two other species of Tetrahymena, $T$. vorax $\mathrm{V}_{2} \mathrm{~S}$, a strain with a low optimal growth temperature $\left(20^{\circ} \mathrm{C}\right)$ and a strain of $\mathrm{T}$. thermophila (Mpr, V) with a high optimal growth temperature of about $38^{\circ} \mathrm{C}$. Typical fluorescence-temperature profiles of both these species are compared with $\mathrm{T}$. pyriformis GL in Figure 8.

Several important observations can be made from the results. The first is that the temperature at which the fluorescence peak occurs is always at a temperature just above the optimal growth temperature. Furthermore, in the case of $T$. pyriformis and $T$. thermophila there is a coincidence between the mid-points of the fluorescence peaks and the optimal shock temperatures for obtaining synchrony of the cells. For $\mathrm{T}$. vorax $\mathrm{V}_{2} \mathrm{~S}$, the mid-point of the fluorescence curve is $27.5^{\circ} \mathrm{C}$, a temperature somewhat lower than that used for obtaining partial synchrony (1). Attempts were subsequently made to synchronise $T$. vorax $V_{2} S$ using a regimen of 30 minute heat shocks at $27^{\circ} \mathrm{C}$ 


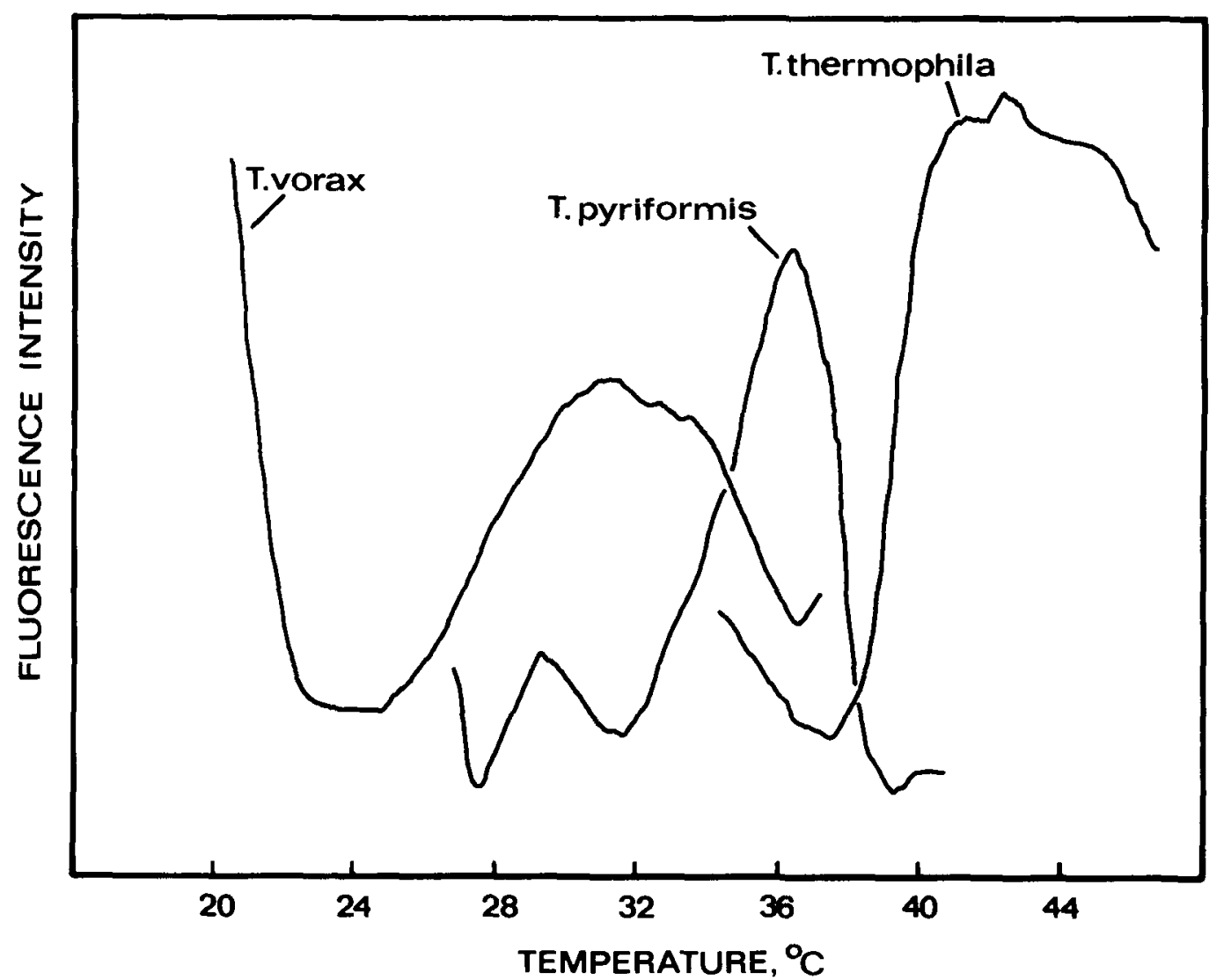

Figure 8. Fluorescence-temperature profiles of three species of Tetrahymena: $T$. vorax $\mathrm{V}_{2} \mathrm{~S}$, washed cell concentration $3.6 \times 10^{4}$ cells $\cdot \mathrm{ml}^{-1}$; T. pyriformis $\mathrm{GL}$, washed cell concentration $6.2 \times 10^{4}$ cells $\cdot \mathrm{ml}^{-1}$; and $\mathrm{T}$. thermophila (Mpr, V), washed cell concentration $10.5 \times 10^{4} \mathrm{cells} \cdot \mathrm{ml}^{-1}$. Conditions of measurement as described in the legend to Figure 4.

interspersed with 40 minutes at $20.2^{\circ} \mathrm{C}$. However, neither this method nor the method of spacing the heat shocks at 1 cell generation apart gave any appreciable degree of synchrony. This lack of success may have been due to the poor growth of the culture in our hands - the generation time at $20.2^{\circ} \mathrm{C}$ was found to be $11 \mathrm{y} / 2$ hours in $1 \%$ proteose peptone $+0.1 \%$ yeast extract with added iron.

Finally, it should be noted that the relative increase of fluorescence with temperature is low in $T$. vorax $\mathrm{V}_{2} \mathrm{~S}$, intermediate with $\mathrm{T}$. pyriformis $\mathrm{GL}$ and high in $\mathrm{T}$. thermophila. The rapidity with which these changes in fluorescence occur reflect the temperature sensitivity of the components which are affected by the heat shock. It is therefore not surprising that the shock tempera- ture for synchrony of $T$. thermophila has to be kept within extremely precise limits in order to obtain optimal synchrony (28).

\section{DISCUSSION}

It is evident from the experiments presented above that there are some components in $T$. pyriformis GL, as well as in other species of Tetrahymena, which respond to an increase in the temperature with an increase in fluorescence. What makes this fluorescence change particularly interesting is that it occurs at a temperature corresponding to the shock temperature used for inducing cell division synchrony. The wavelength maxima for the excitation and emission establish clearly that the fluorescence stems from 
a protein source. Lipid extracts do not show the same spectra, emitting instead at $445 \mathrm{~nm}$, showing that the fluorescence is not due to proteolipids.

It is not known at present whether the protein(s) whose conformation changes around the shock temperature, are merely passive indicators of changes occurring within the cell, or whether they play a more central role in the induction of synchrony. However, several reports have been published showing that the heat shocks which induce synchrony in Tetrahymena cultures cause disturbances to the protein synthesis $(2,3,4,5,18)$. Most recently, it has been reported (25) that tubulin synthesis is repressed by the heat shock, while another paper from this laboratory (11) has demonstrated that while the synthesis of a few proteins is increased as a result of heat shock, the synthesis of most proteins is decreased. The experiments described in the present paper showing that the conformation of certain proteins is changed markedly around the shock temperature confirm early suggestions that this might be the case $(14,30)$. This change in the state of the protein, together with the concomitant inhibition or stimulation of the synthesis of some proteins could well account for the characteristic set-back observed after a heat shock.

Of the trivial explanations for the increase in fluorescence with temperature, the most obvious is that it stems from the growth medium entrapped in the food vacuoles. However, such a possibility is ruled out since the medium itself does not exhibit any temperature-dependent increase in fluorescence (see Figure 2). Furthermore, in a mutant strain of $T$. thermophila incapable of forming vacuoles (strain NPl), the fluorescence peak still occurs (data not shown). It must therefore be concluded that the protein giving rise to the fluorescence signal is an integral part of the cell.

There are three major pools to be considered as the source of the fluorescence signal: the nuclear constituents, the cytoskeletal elements, and the free and bound ribosomes.

A consideration of the events occurring in Tetrahymena upon starvation allows certain conclusions to be drawn. One of the most characteristic changes is a decrease in cell size, which can largely be accounted for by a diminution of the cytoplasmic volume (6). Since the characteristic increase in fluorescence at the shock temperature is not seen in starved cells (Figures $3 a$ and $3 b$ ), it could be argued that the fluorescence signal stems from some cytoplasmic source. However, a diminution in the cell volume is only one of several changes which have been noted in starving Tetrahymena; others include metabolic and energetic changes (6) and fusion of the nucleoli (17).

Turning now to the cytoskeletal proteins, tubulin and actin, it seems likely that neither contribute to the fluorescence change to any great extent, since neither cytochalasin B nor colchicine have any marked effect on the fluorescence, even at millimolar concentrations.

The third major pool of proteins is found in the ribosomes, both free and bound. Thermal denaturation of ribosomes in Tetrahymena has been shown to occur (3), but commences only some $12^{\circ} \mathrm{C}$ higher than the optimal growth temperature. It cannot be ruled out however that the ribosomes in the normal intracellular environment have different conformational and fluorescent properties than the isolated ribosomes. In this respect, it is relevant to recall that cells damaged by shaking or brief low-power sonication, both of which would be expected to alter the ionic milieu, totally lack the characteristic fluorescence.

Whichever protein is responsible, it seems likely that the observed changes in fluorescence are in some way linked with a parallel change in membrane properties. The evidence for this can be summarised as follows:

(a) the fluorescence-temperature profile shifts in the same direction as the culture temperature (see Figures $4 \mathrm{a}$ and $4 \mathrm{~b}$ ). The conformation of a soluble, non-membrane-bound protein is dependent on the amino acid sequence, and the conformation at one particular temperature would not be expected to change just because the cell is cultured at a different temperature. On the other hand, it is now firmly established that the conformation of an integral membrane protein depends on the physical state of the bilayer (12). It has also been shown that the membranes of Tetrahymena regulate their fluidity in response to changes in the ambient temperature $(20,21$, 27). Thus, on increasing or decreasing the culture temperature, compensatory changes in 
the lipid composition of the membrane take place, and as a consequence the conformation of the membrane-associated proteins would be expected to change. It is also possible that the proteins responsible for the fluorescence are not directly associated with the membrane, but their conformation is indirectly controlled by the membrane. One could envisage a situation in which, as a result of changes in the membrane permeability to certain ions, caused by a temperature shift or a change in binding of ions to the membrane, the intracellular ionic milieu could change drastically, and thereby affect the protein conformation.

(b) dense cultures, approaching stationary phase show an increase in fluorescence at higher temperatures than early log phase cultures (Figure 5). It has been shown by ERwiN and BLoch (10) that the proportion of monounsaturated fatty acids decreases in dense cultures. Since the membranes would thus be more rigid, it would be expected, using the same arguments as above, that the temperature at which the changes in protein conformation commence will be correspondingly higher.

(c) dibucaine eliminates the fluorescence signal, whereas cytochalasin $B$ and colchicine do not (Figure 7). As dibucaine is known to affect the properties of phospholipid vesicles $(16,23$, 26) and membranes $(22,24)$, these findings demonstrate that the increase in fluorescence could be membrane-linked. Furthermore, even though dibucaine is also known to affect cytoskeletal structures (22) it would appear that the fluorescence signal does not arise from microtubules or filaments, as neither cytochala$\sin$ B nor colchicine significantly affect the fluorescence.

Although these lines of evidence indicate that changes in the fluorescence with temperature are a result of changes in the membranes, a direct proof is still lacking. The simplest way of establishing such a linkage would be to demonstrate that the fluorescence-temperature profile can be regulated by changing the membrane fluidity. Such a possibility now exists, following the isolation of a fatty acid auxotrophe of $T$. thermophila with an absolute growth requirement for an unsaturated fatty acid (13). In this mutant, supplementation with a particular fatty acid allows the membrane fluidity (13) and composition (unpublished data) to be regulated at will. As has been discussed previously, the conformation, and hence the fluorescence of integral membrane proteins can be regulated by the fluidity of the membrane. Using this mutant, it would thus be expected that the fluorescencetemperature profile would be shifted to increasingly lower temperatures as the fluidity of the membrane was increased by suitable fatty acid supplementation of the cultures. Such a correlation, although demonstrating a link between the fluorescence increase and membrane fluidity, would not prove that the signal stems from an integral membrane protein. For this, other experiments will have to be designed.

Finally, it would be interesting to establish if any correlation exists between the inflection points of the fluorescence curves obtained in mutants of different membrane fluidity, and the shock temperature required for inducing synchrony.

\section{ACKNOWLEDGEMENTS}

R. J. Hill would like to express his deep appreciation to colleagues at the Biological Institute for help after the death of professor ZEUTHEN for valuable discussions, and in particular to Dr. Helge A. Andersen for advice and support during the final phase of writing this manuscript.

\section{REFERENCES}

1. Buhse, H. E. Jr. \& L. Rasmussen: A method for synchronization of cell division and macrostome formation in the ciliate Tetrahymena vorax. Compt. Rend. Trav. Lab. Carlsberg 40, 59-67 (1974)

2. Byfield, J. E. \& Y. C. LeE: The effect of synchronizing temperature shifts on the synthesis and translation of replication supporting messengers in Tetrahymena pyriformis. Exptl. Cell Res. 61, 42-50 (1970)

3. Byfield, J. E., Y. C. LeE \& L. E. BennetT: Thermal instability of Tetrahymena ribosomes: effects on protein synthesis. Biochem. Biophys. Res. Commun. 37, 806-812 (1969)

4. Byfield, J. E. \& O. H. Scherbaum: Temperature-dependent decay of RNA and of protein synthesis in a heat-synchronized protozoan. Proc Nat. Acad. Sci. USA 57, 602-606 (1967)

5. Byfield, J. E. \& O. H. Scherbaum: Temperature 
effect on protein synthesis in a heat-synchronized protozoan treated with actinomycin D. Science $156,1504-1505$ (1967)

6. CAMERoN, I. L.: Growth characteristics of Tetrahymena. In: Biology of Tetrahymena, A. M. Elliott ed., Dowden, Hutchinson \& Ross Inc., Stroudsburg, Pennsylvania, pp 199-226 (1973)

7. Chen, R. F., H. Edelhoch \& R. F. Stenner: Fluorescence of proteins. In: Physical principles and techniques of protein chemistry, Part A, S. J. Leach ed., Academic Press, New York and London, pp 171-244 (1969)

8. Conner, R. L. \& B. Y. Stewart: The effect of temperature on the fatty acid composition of Tetrahymena pyriformis WH-14. J. Protozool. 23, 193-196 (1976)

9. Erwin, J. A.: The reversal of temperatureinduced cell surface deformation in Tetrahymena by polyunsaturated fatty acids. Biochim. Biophys. Acta 202, 21-34 (1970)

10. Erwin, J. A. \& K. BLoCH: Lipid metabolism of ciliated protozoa. J. Biol. Chem. 238, 16181624 (1963)

11. FinK. K. \& E. Zeuthen: Heat shock proteins in Tetrahymena studied under growth conditions. Exptl. Cell Res. in press (1980)

12. Gennis, R. B. \& A. Jonas: Protein-lipid interactions. Annu. Rev. Biophys. Bioeng. 6, 195-238 (1977)

13. HILL, R. J.: Modulation of membrane fluidity in a fatty acid auxotrophe of Tetrahymena thermophila. Biochim. Biophys. Acta 595, 140-145 (1980)

14. Holz, G. G., O. H. Scherbaum \& N. Williams: The arrest of mitosis and stomatogenisis during temperature-induction of synchronous division in Tetrahymena pyriformis, mating type 1, variety 1. Exptl. Cell Res. 13, 618-621 (1957)

15. Kramhørt, B. \& E. Zeuthen: Synchronization of cell divisions in the fission yeast, Saccharomyces pombe, using heat shocks. Compt. Rend. Trav. Lab. Carlsberg 38, 351-368 (1971)

16. LEE, A. G.: Interactions between amine anæsthetics and lipid mixtures. Biochim. Biophys. Acta 448, 34-44 (1976)

17. Levy, M. R. \& A. M. Eluotr: Biochemical and ultrastructural changes in Tetrahymena pyriformis during starvation. J. Protozool. 15. 208-222 (1968)

18. Levy, M. R., C. E. Gollon \& A. M. Elliott: Effects of hyperthermia on Tetrahymena pyriformis. I. Localization of acid hydrolases and changes in cell ultrastructure. Exptl. Cell Res. 55, 295-305 (1969)

19. Lo, H. K., D. JASPER \& J. A. ERWIN: Ultrastructural alterations in Tetrahymena pyri- formis induced by growth on saturated phospholipids at $40.1^{\circ} \mathrm{C}$. Tissue \& Cell 8, 19-32 (1976)

20. Martin, C. E., K. Hiramitsu, Y. Kitajima, Y. Nozawa, L. Skriver \& G. A. Thompson Jr.: Molecular control of membrane properties during temperature acclimation. Fatty acid desaturase regulation of membrane fluidity in acclimating Tetrahymena cells. Biochemistry 15, 52185227 (1976)

21. Martin, C. E. \& G. A. Thompson Jr.: Use of fluorescence polarisation to monitor intracellular membrane changes during temperature acclimation. Correlation with lipid compositional and ultrastructural changes. Biochemistry 17, 35813586 (1978)

22. Nicolson, G. L. \& G. Poste: Cell shape changes and transmembrane receptor uncoupling induced by tertiary amine local anæsthetics. J. Supramol. Struct. 5, 65-72 (1976)

23. Papahadjopoulos, D., K. Jacobson, G. Poste \& G. SHEPHERD: Effects of local anæsthetics on membrane properties. I. Changes in the fluidity of phospholipid bilayers. Biochim. Biophys. Acta 394, 504-519 (1975)

24. Poste, G., D. Papahadjopoulos, K. Jacobson \& W. J. VAlL: Effects of local anæsthetics on membrane properties. II. Enhancement of the susceptibility of mammalian cells to agglutination by plant lectins. Biochim. Biophys. Acta $394,520-539$ (1975)

25. Ron, A. \& E. Zeuthen: Tubulin synthesis and heat shock induced cell synchrony in Tetrahymena. Exptl. Cell Res. in press (1980)

26. Singer, M. A.: Interaction of dibucaine and propranolol with phospholipid bilayer membranes - effect of alterations in fatty acyl composition. Biochem. Pharmac. 26, 51-57 (1977)

27. Skriver, L. \& G. A. Thompson Jr.: Temperature-induced changes in fatty acid unsaturation of Tetrahymena membranes do not require induced fatty acid desaturase synthesis. Biochim. Biophys. Acta 572, 376-381 (1979)

28. Surr-Jessen, P.: Heat synchronization of cell division in Tetrahymena thermophila and a mutant, NP1, with a temperature sensitive defect for oral developement. Carlsberg Res. Commun. 43, 255-263 (1978)

29. ZeuTheN, E.: Synchrony in Tetrahymena by heat shocks spaced a normal cell generation apart. Exptl. Cell Res. 68, 49-60 (1971)

30. Zeuthen, E. \& N. E. Williams: Divisionlimiting morphogenetic processes in Tetrahymena. In: Nucleic acid metabolism, cell differentiation and cancer growth, E. V. Cowdry \& $\mathbf{S}$. Seno eds. Pergamon Press, Oxford, pp 203-216 (1969) 